\title{
Surgical Treatment of Peripheral Vertigo and Vertiginous Diseases
}

\author{
Nebil Göksu Yıldırım A. Bayazıt Metin Yılmaz İsmet Bayramoğlu \\ Department of Otolaryngology and Head and Neck Surgery, Faculty of Medicine, Gazi University, Besevler, \\ Ankara, Turkey
}

\section{Key Words}

Vertigo $\cdot$ Surgery $\cdot$ Neuro-otology $\cdot$ Vertiginous disease

\begin{abstract}
Although our understanding of the mechanisms of vertigo and pathophysiology of vertiginous disorders has increased, diagnosis and treatment of various vertiginous diseases is challenging. The objective for the treatment of a vertiginous disease is to eliminate the underlying pathology either with maneuvers or drugs. In vertiginous diseases, surgery is performed either to eliminate the underlying pathologic event or to create stability in the incoming vestibular signals. It is not always possible to treat the underlying disease. Therefore, surgery is usually performed for the relief of vertigo. There are various surgical approaches used to treat a variety of vertiginous diseases. Selection of the approach depends on the type of vertiginous disease. This review mainly focuses on the current status and outcome of the surgeries used in the treatment of a variety of vertiginous diseases.
\end{abstract}

Copyright $@ 2005$ S. Karger AG, Basel

\section{Introduction}

The vestibular system is formed by the vestibular end organ in the inner ear (utricle, saccule and semicircular canals), vestibular nerve and vestibular nuclei in the brainstem and related subcortical structures. There are two vestibular systems, one on the right and the other on the left side.

The vestibular end organ is the site where mechanical energy produced by the flow of endolymph is converted to electrical energy through deflection of steriocilia of the hair cells. The right and left vestibular end organs act as pairs. The utricle, saccule and lateral semicircular canal on one side are paired with their counterparts on the contralateral side. The posterior semicircular canal is paired with the superior semicircular canal on the contralateral side and vice versa. Each pair produces equal discharges in opposite directions, i.e. as one is hyperpolarized the other is depolarized. These polarizations occurring in a push-pull fashion represent symmetricity of the peripheral vestibular apparatus. Discharges reach the ipsilateral vestibular nuclei in the brainstem. Vestibular nuclei, which contain the second-order neurons, can modify incoming signals and make spinal, ocular, cerebellar and cerebral connections.

Asymmetry between both vestibular systems produces a hallucination of motion, that is vertigo. When a disorder causes this asymmetry, vestibular nuclei can modify incoming signals in a few days and make them symmetrical.

Prof. Dr. Nebil Göksu

Mithatpasa Cad. No: 51/12

Emek Apartmanı

TR-06420 Kizilay/Ankara (Turkey)
Fax + 41613061234 E-Mail karger@karger.ch www.karger.com
() 2005 S. Karger AG, Basel

Accessible online at: www. karger.com/orl 
Table 1. The diseases in which surgical treatment of vertigo is warranted

Benign paroxysmal positional vertigo

Idiopathic (Ménière's disease), secondary or delayed endolymphatic hydrops

Recurrent vestibulopathy

Recurrent vestibular neuronitis

Labyrinthitis

Perilymphatic fistula

Pontocerebellar lesions (acoustic neuroma, arachnoid cyst or adhesion, other tumors)

Neurovascular compression syndrome

Others (intractable vertigo due to other ear pathologies like syphilis or trauma)

This is referred to as vestibular compensation, which is related to the plasticity of the vestibular nuclei. However, when fluctuations occur in the incoming signals, vestibular adaptation or compensation cannot occur, because vestibular nuclei like stability rather than instability in the incoming signals. This is the rationale for vertigo surgery, which helps adaptation of the vestibular nuclei by creating stability in the stimuli coming from the periphery.

Although our understanding of the mechanisms of vertigo and pathophysiology of vertiginous disorders has increased, diagnosis and treatment of various vertiginous diseases is challenging. The objective for the treatment of a vertiginous disease is to eliminate the underlying pathology either with maneuvers or drugs. When this is not possible, surgery is performed as a symptomatic treatment for the relief of the most devastating symptom of the vertiginous disease, that is vertigo.

There are various surgical approaches used to treat vertigo. Selection of the approach depends on the type of the vertiginous disease. Surgical treatment of vertigo is mostly performed for Ménière's disease, and rarely for other disorders (table 1). In this review, we will not go into detail of the surgical techniques. Rather, we will mainly focus on the current status and outcome of the surgeries used in the treatment of a variety of vertiginous diseases.

\section{Indications for Surgery}

Vertigo surgery can be performed primarily for a vertiginous disease like Ménière's disease, or to treat vertigo that occurred as a complication of a disease process like labyrinthitis. Surgical treatment of vertigo can also be divided into two main categories: (1) hearing preserved,
Table 2. Surgical techniques used to treat vertigo and vertiginous disease

Benign paroxysmal positional vertigo

Singular neurectomy

Posterior canal plugging

Ménière's disease and delayed endolymphatic hydrops

Saccotomy (Cody tack procedure)

Cochleosacculotomy

Labyrinthectomy

Transcanal

Transmastoid

Transmeatal-transcanal cochleovestibular neurectomy

Chemical perfusion of the ear

Aminoglycosides

Corticosteroids

Endolymphatic sac surgery

Decompression

Shunt with or without alloplastic tube

Endolymphatic sac-subarachnoid shunt

Endolymphatic sac-mastoid shunt

Endolymphatic sac-vein

Vestibular neurectomy

Middle fossa

Posterior fossa

Retrolabyrinthine

Retrosigmoid-internal acoustic canal

Combined retrolabyrinthine-retrosigmoid

Combined retrolabyrinthine-retrosigmoid endolymphatic

system surgery

Recurrent vestibulopathy

\section{Labyrinthitis}

Labyrinthectomy

Vestibular neurectomy

Perilymphatic fistula

Fistula repair, sealing

Pontocerebellar pathology

Concomitant vestibular neurectomy

Neurovascular compression syndrome (vestibular paroxysm)

Decompression

Vestibular neurectomy

Other diseases complicated by vertigo

Vestibular neurectomy

Labyrinthectomy

and (2) hearing destructed. There are numerous surgical techniques used to treat vertigo or vertiginous disease (table 2). Indication for surgical treatment of peripheral vertigo is based on (1) accurate diagnosis of peripheral vertigo; (2) previous trial of medications and lack of response to medical therapy; (3) general health of the patient must be suitable for a surgical procedure and compensation to 
occur, and (4) willingness of the patient to undergo surgery for the relief of incapacitating vertigo to increase his/ her quality of life.

\section{Benign Paroxysmal Positional Vertigo}

Gravity-sensitive free-floating endolymph particles in the posterior semicircular canal, otoconia displaced from the otolithic membrane in the utricle, underlie most cases of benign paroxysmal positional vertigo (BPPV). Over $90 \%$ of patients can be successfully treated with a simple outpatient maneuver that moves the particles back into the utricle [1]. Surgery is required in few patients. In our experience, less than $2 \%$ of patients need surgery for BPPV.

\section{Singular Neurectomy}

Gacek [2] developed selective sectioning of the posterior ampullary or singular nerve in 1974. This procedure is referred to as singular neurectomy and has been used in the surgical treatment of BPPV. It is a deafferentation surgery, which prevents irreversibly conduction of discharges elicited in the posterior semicircular canal. With singular neurectomy, complete relief of BPPV can be achieved in $96.8 \%$, whereas sensorineural hearing loss may occur in $3.7 \%$ [3]. The operation has rarely been performed recently.

\section{Posterior Canal Occlusion}

This procedure irreversibly stops flow of the endolymph, and in turn deflection of the cupula. Thus, transduction mechanism in the posterior canal cupula is inhibited indirectly, and the canal cannot elicit discharge anymore. The occlusion can be made by mechanical means or laser (argon or carbon dioxide), both of which have a similar outcome though the incidence of postoperative disequilibrium is less with the latter [4, 5]. Canal occlusion is a very effective technique with a low risk to hearing [6]. Although hearing loss can occur in canal plugging, it may return to the preoperative state [7]. It is important to occlude the canal completely. Otherwise, recurrence of BPPV and iatrogenic fistula are likely to occur [8].

\section{Endolymphatic Hydrops}

Hydrops of the endolymph can be idiopathic as in Ménière's disease, delayed type or secondary to another disease. Etiopathogeneses of the hydrops have not been understood completely in these disorders. In delayed endolymphatic hydrops, the patient has audiometric findings consistent with Ménière's disease, but vertigo occurs later in the course of hydrops. Secondary endolymphatic hydrops occurs as a result of another disease like syphilis. Ménière's disease involves idiopathic endolyphatic hydrops; there is no associated disorder that can cause the symptoms. Surgical treatment is warranted in about $10 \%$ of patients with Ménière's disease, and numerous surgical modalities have been developed and applied. In the majority of patients, we cannot cure the vertiginous disease, but we can treat vertigo. Bilaterality is an important issue in Ménière's disease and affects selection of treatment modality. Almost $17 \%$ of medically treated and $5.9 \%$ of surgically treated patients have bilateral disease [9]. Children comprise almost $1.5 \%$ of all patients with Ménière's disease, and sac operation or vestibular neurectomy can be performed [10]. These surgical interventions should also be preferred in bilateral disease, whereas inner perfusion should be avoided.

\section{Sacculotomy and Cochleosacculotomy}

Endolymphatic hydrops with dilation of the saccule is radiologically evident in Ménière's disease. Sacculotomy includes drainage of the dilated saccule with resultant elimination of the hydrops. Despite the presence of modifications in sacculotomy techniques, the Cody tack procedure was the most popular sacculotomy operation, in which a $1.5-$ to $1.7-\mathrm{mm}$-long stainless steel tack is placed through the stapes footplate to allow drainage as the saccule is distended. This operation may be preferred when the patients have a hearing loss in the hydropic ear, because almost $50 \%$ of patients will have a hearing loss despite a vertigo control rate of more than $60 \%$ [11].

Schuknecht [12] developed cochleosacculotomy by creating a fistula between the perilymph and endolymph via a round window approach. Although a vertigo control rate of more than $80 \%$ was reported $[13,14]$, it is not advocated because long-term control of vertigo is poor, and $30-80 \%$ of patients will have a significant hearing loss [15]. Recently, cochleosacculotomy has rarely been performed and may be considered in old patients with Ménière's disease [16].

\section{Intratympanic Chemical Perfusion of the Inner Ear}

Schuknecht [17] first introduced perfusion of the middle ear with aminoglycosides in 1956. This treatment modality has been popular with many otolaryngologists because of ease of application for both the patient and otolaryngologist. It can be performed in an office setting, 
and perfusion of the inner ear with a high concentration of medications can be made while avoiding their systemic side effects.

Inner ear perfusion methods vary, and include transtympanic injection, sustained release devices (Silverstein MicroWick; Micromedics, Eaton, Minn., USA), microcatheter placement to the round window (Durect Corp., Cupertino, Calif., USA), and injection onto Gelfoam placed in the round window.

Different medications and chemicals have been used for perfusion of the inner ear. Streptomycin perfusion was made in the past [18]. Recently, dexamethasone and gentamicin have been used most commonly. The use of intratympanic gentamicin has been investigated as an alternative treatment to vestibular nerve section or labyrinthectomy. However, with regard to selection of medication, dosage, mode of application and repetition rate of the procedure, the protocols for inner ear perfusion have not been standardized yet.

Vertigo control rate with intratympanic injection of dexamethasone ranges from 43 to $72 \%[19,20]$, and trials of the significance of dexamethasone perfusion are still continuing. Intratympanic gentamicin therapy has become the most frequently performed invasive procedure for treatment of Ménière's disease with a success rate of control of vertigo ranging from 71.4 to $100 \%$ [21, 22]. This vertigo control rate is comparable with vestibular nerve section. Intratympanic gentamicin can also be used to control vertigo in patients with Ménière's disease who have persistent vertigo after unsuccessful endolymphatic sac surgery [23], although this issue is debated [24]. It was suggested that hearing results of intratympanic gentamicin are not different from those of natural control, of endolymphatic sac surgery, and of vestibular nerve section [25]. Despite this report, hearing loss can be seen up to $75 \%[21,22]$. Therefore, hearing preservation seems a drawback in gentamicin perfusion. Bilateral Ménière's disease is also a limitation for gentamicin perfusion, because it may result in chronic imbalance and bilateral hearing loss. However, cochlear implantation can be performed in hearing loss occurring due to inner ear perfusion.

\section{Labyrinthectomy}

This procedure is an ablative surgery resulting in the loss of both cochlear and vestibular functions. The surgery can be performed in different ways starting from destruction of the semicircular canals to removal of the inner ear entirely. Advanced age is not a contraindication [26]. Transmastoid labyrinthectomy, which was popularized by Cawthorne [27], may be preferable to transcanal labyrinthectomy, because the incidence of permanent posttreatment imbalance is less with the former [28].

In labyrinthectomy, an incomplete removal of preganglionic vestibular tissue may cause continued or recurrent physiologic function resulting in further vertigo. Therefore, labyrinthectomy can be combined with vestibular nerve sectioning. However, transmastoid labyrinthectomy and a translabyrinthine vestibular nerve section were shown to offer the same benefit in the control of intractable episodic vertigo [29]. It was also suggested that longterm clinical balance and hearing outcomes of transmastoid labyrinthectomy and retrosigmoid vestibular neurectomy are equivalent with a vertigo control rate exceeding $90 \%[30,31]$. This contention can be considered true when labyrinthectomy is performed completely without leaving a residual vestibular tissue.

When we consider the possibility of bilateral occurrence of Ménière's disease, it is risky to perform labyrinthectomy, which causes hearing loss. Labyrinthine fibrosis and ossification are seen after labyrinthectomy, which is a limitation when cochlear implantation is needed, particularly in bilateral cases. Therefore, labyrinthectomy has been a rare procedure and should be considered in selected patients.

\section{Endolymphatic Sac Surgery}

Portmann [32] introduced endolymphatic sac decompression in 1926. Since then, sac surgery has been improved and modified, including endolymphatic sac-vein decompression and endolymphatic sac shunt.

In the endolymphatic sac-vein decompression procedure, decompression of the sigmoid sinus, posterior cranial fossa dura and endolymphatic sac is performed. According to long-term follow-up results, this surgery is safe and efficient to control vertigo and for stabilization of hearing [33]. Vertigo control rate ranges from 85 to $100 \%$, and hearing stabilization or improvement can be achieved in almost 85\% [34].

Endolymphatic sac shunt surgery is another modification of the sac surgery, in which a shunt is created between the sac and mastoid cavity or between the sac and subarachnoid space. Treatment results of the endolymphatic subarachnoid shunt were reported to be comparable with the endolymphatic mastoid shunt in Ménière's disease $[35,36]$. However, in the long term after endolymphatic sac shunt surgery, fibrosis or reclosure of the sac incision may cause deterioration of the outcome. Intraoperative application of mitomycin $\mathrm{C}$ to the incised sac may be beneficial in this case [37]. Steroid instillation during surgery 
may improve vertigo control and hearing stabilization while decreasing tinnitus [38]. Vertigo control occurs in $60-70 \%$ in sac shunt surgery $[35,39]$. Despite these facts, it was argued that the impact of the various endolymphatic sac shunts on the symptoms of patients with Ménière's disease is most likely caused by a placebo effect [39]. Other studies supported the concept of a placebo effect of sac shunt operations. Insertion of a ventilating tube in the tympanic membrane and complete removal of the extraosseous endolymphatic sac and cortical mastoidectomy gave similar results to sac shunt operation [40-42]. However, proper application of the surgical procedure seems critical, because sac anatomy shows variations, and the surgeon may have difficulty in entering and enlarging the sac lumen in some cases. This condition may affect the outcome of the surgery. Preservation of sac integrity is also important. An appropriate surgery may result in $90 \%$ vertigo control rate [43].

Sac surgery can be done in childhood or in the elderly, in patients with unilateral hearing loss, and in the case of coexistence of Ménière' disease with other ear diseases like fistula, otitis media and otosclerosis. It can be performed bilaterally. However, sac surgery is not applicable for vertiginous conditions other than endolymphatic hydrops. The surgery may result in hearing loss in $2 \%$, which is attributed to infection or inflammation rather than the surgical procedure itself [24]. Although the value of the endolymphatic sac surgery is conflicting, it has been one of the most common surgical procedures performed in Ménière's disease $[24,43,44]$.

\section{Transmeatal-Transcanal Cochleovestibular \\ Neurectomy}

This is an extended transcanal labyrinthectomy in which the cochlear and vestibular nerves are cut at the lateral end of the internal acoustic canal as well. This surgery has been used most commonly in Ménière's disease, and rarely in chronic labyrinthitis occurring after stapes, middle ear or mastoid surgery. Vertigo and tinnitus control rates are 84 and $65 \%$, respectively [45]. Transmeataltranscanal cochleovestibular neurectomy has not been commonly performed by now because of introduction of more precise vertigo control techniques and it eliminates the chance for cochlear implantation. For these reasons, the authors also gave up performing this procedure in vertigo surgery.

\section{Vestibular Nerve Section}

This is a deafferentation surgery for vestibular impulses. It can be performed via several routes using differ- ent techniques. In 1904, Frazier [46] first performed posterior fossa sectioning of the eighth nerve, which was popularized by McKenzie [47] and Dandy [48] in the early 1930s. The middle fossa approach was first introduced by Perry [49] in 1904, and improved by House [50] in 1961. Later, Fisch [51] and Glasscock et al. [52] modified and popularized vestibular nerve sectioning. The infralabyrinthine approach was introduced by Vernick [53] in 1990, but did not see wide acceptance. Silverstein and Norrell [54] and Silverstein et al. [55, 56] used the retrolabyrinthine approach in 1978, retrosigmoid-internal acoustic canal approach in 1985, and retrosigmoid-retrolabyrinthine approach in 1987.

The middle and posterior fossa approaches are most commonly used to selectively section the vestibular nerve. In the internal acoustic canal, cochlear and vestibular nerves form separate bundles, therefore selective vestibular neurectomy can be performed completely. The middle fossa approach is convenient to reach the internal acoustic canal and selectively cut the vestibular nerve. However, landmarks are not consistent, and there is a risk of injuring the facial nerve and cochlea unless the surgeon is experienced. Adhesions in the middle fossa dura seen in the elderly may have an impact on the surgical approach. The posterior fossa approach includes different techniques. The retrosigmoid-internal acoustic canal technique can lead to postoperative headache because of drilling in the internal acoustic canal. The incidence of cerebrospinal fluid leakage is high in the retrolabyrinthine technique. So far, the combined retrosigmoid-retrolabyrinthine technique has been the most common approach for selective vestibular nerve section.

In the retrosigmoid-retrolabyrinthine technique, it is possible to selectively cut the vestibular nerve according to the following criteria: (1) the vestibular nerve forms the cranial portion of the vestibulocochlear nerve in the cisternal portion; (2) the vestibular nerve portion contains 18,000 fibers and looks grayish, while the cochlear nerve portion contains 31,000 fibers and looks white; (3) there is a demarcation line or septum between the cochlear and vestibular nerves in almost $75-80 \%$ of cases [46, 51, 52], and (4) in the absence of the other criteria, the superior half of the cochleovestibular nerve can be cut to perform selective vestibular neurectomy. The retrosigmoid-retrolabyrinthine technique also allows for inspection of the other cranial nerves (5-11) as well as any vascular compression.

Vestibular neurectomy is an effective procedure for relieving vertigo in intractable Ménière's disease with a success rate of 90-100\% while preserving hearing in most 
of the patients [57]. It was shown that vertigo control results of vestibular neurectomy are better than those of endolymphatic sac surgery [58], whereas hearing results of both procedures are similar [59]. Tinnitus control with vestibular neurectomy is better than with endolymphatic sac surgery [60]. According to our results in 116 patients with Ménière's disease, concurrent endolymphatic sacsubarachnoid shunt surgery and vestibular nerve section does not improve hearing or tinnitus outcome over vestibular nerve section alone [61]. Similar results were also reported by other researchers [62]. Accordingly, a beneficial effect of endolymphatic sac-subarachnoid shunt surgery seems questionable in Ménière's disease.

Most of the other surgical procedures like sac surgery and labyrinthine perfusion are used only in the surgical treatment of endolymphatic hydrops. However, vestibular neurectomy can be applied in a wide spectrum of diseases like endolymphatic hydrops, recurrent vestibulopathy, recurrent vestibular neuronitis and labyrinthine fibrosis. Cochlear implantation can be successfully performed after vestibular neurectomy as well. Elderly population and the presence of a severe systemic disease may be limitations for vestibular neurectomy due mainly to the possibility of inefficient postoperative vestibular compensation.

The authors favor retrosigmoid-retrolabyrinthine vestibular neurectomy for the treatment of intractable peripheral vertigo, and they have operated on more than 280 patients with Ménière's disease since 1991. Despite some minor complications like cerebrospinal fistula $(<0.5 \%)$, no major complications have been observed. The long-term ( $>2$ years) vertigo control $(>95 \%)$ and hearing preservation $(81 \%)$ rates have been satisfactory. In our experience, in spite of being a posterior fossa approach, retrosigmoid-retrolabyrinthine vestibular neurectomy is a safe and effective operation.

\section{Other Surgical Interventions}

Middle ear muscle tenotomy and ventilation tube insertion may be performed in Ménière's disease. In a trial of middle ear muscle tenotomy, sectioning of the tensor tympani and stapedius muscle tendons significantly reduced the frequency and intensity of vertigo and improved hearing and tinnitus in 2 years of follow-up [63]. In another trial of insertion of a ventilation tube in the tympanic membrane, vertiginous attacks were controlled in $82 \%$ in 2 years of follow-up, and it was suggested that patients with endolymphatic hydrops are particularly sensitive to middle ear pressure [64]. The significance of these interventions is subjected to discussion.

\section{Neurovascular Compression}

The concept of vascular compression syndrome has evolved and is considered in the etiology of various diseases including trigeminal neuralgia, hemifacial spasm, vertigo and neurogenic or essential hypertension $[65,66]$. Vascular compression of the eighth nerve usually manifests itself by disabling positional vertigo and occasionally by Ménière's disease-like symptoms. The anterior inferior cerebellar artery forms a loop around the vestibulocochlear nerve in the majority of cases, while compression caused by the vertebral artery and posterior inferior cerebellar artery is rare.

Diagnosis can be made according to history, physical findings, audiological assessment, vestibular function testing, auditory brainstem evoked responses, air contrast computed tomography or magnetic resonance imaging [67-69]. History is very important in the diagnosis and differential diagnosis of vertiginous diseases. The value of vestibular function tests is limited to giving an objective clue about the presence and side of the vertiginous process. Computed tomography also has a limited value, and air contrast computed tomography is not used anymore. Prolongation of wave I-III interval on auditory brainstem testing is an important clue regarding compression of the vestibulocochlear nerve. Magnetic resonance imaging is an important tool to demonstrate the existence of a vascular compression.

Decompression of the vestibulocochlear nerve should be performed in the early phase of the disease, since cochlear and vestibular functions are irreversibly impaired if neurovascular compression continues for a long period of time [70]. The patients with vertigo due to vascular compression have been treated surgically by separating the vascular loop from the nerve [71], proceeded by the placement of a piece of muscle tissue or Teflon between the vessel and the nerve. Occasionally, vestibular nerve resection or section medial to the vascular loop relieves vertigo [72]. In our experience, neurovascular compression is an important clinical entity rather than being a fiction. In particular, it should be considered in the differential diagnosis of disabling positional vertigo. According to our observations, the compression site is usually in the root entry zone of the cochleovestibular nerve due to the anterior inferior cerebellar artery being the most common cause of compression. The combined retrosigmoid-retrolabyrinthine approach is convenient to gain access to the compression site. The adjunctive use of endosopes is of the utmost importance to evaluate the neurovascular relationship precisely. This approach will also allow simultaneous vestibular neurectomy as indicated. 


\section{Perilymphatic Fistula}

Fistula is defined as an abnormal communication between the middle and inner ear, and can occur spontaneously, in the course of a middle ear infection or after a trauma (barotrauma, iatrogenic and fracture). Vertigo may be absent, or can occur spontaneously or with pressure changes affecting the inner ear. There is no unique test to diagnose a fistula. Despite this diagnostic controversy, many still operate when this condition is suspected based on history and symptoms. Diagnosis can be made when the fistula has been seen intraoperatively. When the fistula is seen, the simplest way to repair is to seal it with cartilage, bone dust mixed with fibrin glue, temporalis fascia or pedicled temporalis muscle [73]. Despite the presence of signs and symptoms suggesting a perilymph fistula, it is not possible to find a fistula in every operation. In this case, oval and round window packing can be made at the time of surgical exploration. These will usually help to control vertigo. Occasionally, adjunct modalities (endolymphatic shunt, labyrinthectomy, blocking a cochlear aqueduct and streptomycin ablation) can be used to control vertigo [74]. Coexistence of perilymphatic fistula and Ménière's disease is possible. In this case, fistula repair is performed first, reserving other vertigo surgeries as a secondary procedure if needed [75]. In children, surgical repair of the fistula results in stabilization of hearing in $10 \%$ and vertigo control in $71 \%$ [76].

\section{Pontocerebellar Lesions}

Acoustic neuroma is the most common pontocerebellar tumor requiring surgery. The tumor usually arises from the vestibular nerve, especially from the superior vestibular nerve. Patients usually experience dizziness or unsteadiness rather than vertigo attacks. Slow tumor growth, which allows for vestibular compensation to occur, is the cause of dizziness instead of true vertigo [77]. The vestibular nerve is cut during surgical excision of the tumor. That sudden deafferentation of the vestibular signals leads to postoperative vertigo. But vestibular compensation starts a few days after the operation and is completed in several months.

Arachnoid cyst can also cause dizziness and rarely vertigo. Magnetic resonance imaging is helpful in the diagnosis. Surgical excision of the cyst is enough to relieve the symptoms. Vestibular neurectomy is needed occasionally.

\section{Other Diseases}

Vertigo can occur due to rare disorders of the inner ear like labyrinthine fibrosis or in the course of a systemic disease like syphilis or Cogan syndrome that may impact on inner ear functions. Medical treatment of the underlying disease may help to reverse inner ear functions with resultant elimination of vertigo. Otherwise, surgical treatment is considered that mostly includes labyrinthectomy or vestibular neurectomy.

\section{Conclusion}

An effective and permanent method of relief in Ménière's disease is debated, and medical and surgical treatments are controversial [78]. Endolymphatic sac surgery is the only nondestructive procedure for Ménière's disease though its benefit is debated. Destructive procedures such as labyrinthectomy and vestibular nerve section are usually reserved for cases of failure or recurrence [79]. Recently, the number of vestibular neurectomies, labyrinthectomies, and endolymphatic sac surgeries has decreased. Meanwhile, the use of office-administered intratympanic gentamicin therapy has increased rapidly, and it has become the most frequently used invasive treatment for Ménière's disease [80].

The majority of surgeries are used only for relief of vertigo in Ménière's disease. However, vestibular neurectomy can be used in the surgical treatment of vertigo in a variety of vertiginous disorders. It has a low complication and high success rate, and can be applied as an initial surgery or reserved as the last step in the treatment of vertigo, depending upon the preference of both the patient and surgeon. 


\section{References}

1 Parnes LS, Agrawal SK, Atlas J: Diagnosis and management of benign paroxysmal positional vertigo (BPPV). CMAJ 2003; 169:681-693.

$\checkmark 2$ Gacek RR: Transection of the posterior ampullary nerve for the relief of benign paroxysmal positional vertigo. Ann Otol Rhinol Laryngol 1974;83:596-605

$\checkmark 3$ Gacek RR, Gacek MR: Results of singular neurectomy in the posterior ampullary recess. ORL J Otorhinolaryngol Relat Spec 2002;64: 397-402.

4 Anthony PF: Laser applications in inner ear surgery. Otolaryngol Clin North Am 1996;29: 1031-1048.

$\checkmark 5$ Antonelli PJ, Lundy LB, Kartush JM, Burgio DL, Graham MD: Mechanical versus $\mathrm{CO}_{2}$ laser occlusion of the posterior semicircular canal in humans. Am J Otol 1996;17:416-420.

$\checkmark 6$ Agrawal SK, Parnes LS: Human experience with canal plugging. Ann NY Acad Sci 2001; 942:300-305.

7 Parnes LS, McClure JA: Posterior semicircular canal occlusion in the normal hearing ear. Otolaryngol Head Neck Surg 1991;104:52-57.

$>8$ Rizvi SS, Gauthier MG: Unexpected complication of posterior canal occlusion surgery for benign paroxysmal positional vertigo. Otol Neurotol 2002;23:938-940.

$>9$ Rosenberg S, Silverstein H, Flanzer J, Wanamaker H: Bilateral Ménière's disease in surgical versus nonsurgical patients. Am J Otol 1991;12:336-340.

-10 Mizukoshi K, Shojaku H, Aso S, Asai M, Watanabe Y: Ménière's disease and delayed endolymphatic hydrops in children. Acta Otolaryngol Suppl 2001;545:6-9.

11 McDonald TJ, Cody TR: The sacculotomy procedure. Otolaryngol Clin North Am 1995;27: 403-412.

12 Schuknecht HF: Cochleosacculotomy for Ménière's disease. Theory, technique, and results. Laryngoscope 1982;92:853-858.

$\checkmark 13$ Montandon PB, Hausler RJ, Kimura RS: Treatment of endolymphatic hydrops with cochleosacculotomy. Clinical results and experimental findings. Otolaryngol Head Neck Surg 1985;93:615-621.

14 Dionne J: Cochleosacculotomy. J Otolaryngol 1985;14:59-61.

-15 Giddings NA, Shelton C, O’Leary MJ, Brackmann DE: Cochleosacculotomy revisited. Long-term results poorer than expected. Arch Otolaryngol Head Neck Surg 1991;117:1150 1152.

-16 Kinney WC, Nalepa N, Hughes GB, Kinney SE: Cochleosacculotomy for the treatment of Ménière's disease in the elderly patient. Laryngoscope 1995; 105:934-937.

17 Schuknecht HF: Ablation therapy for the relief of Ménière's disease. Laryngoscope 1956;66: 859-870.

18 Shea JJ: Perfusion of the inner ear with streptomycin. Am J Otol 1989;10:150-155.
19 Barrs DM, Keyser JS, Stallworth C, McElveen JT Jr: Intratympanic steroid injections for intractable Ménière's disease. Laryngoscope 2001;111:2100-2104.

20 Sennaroglu L, Sennaroglu G, Gursel B, Dini FM: Intratympanic dexamethasone, intratympanic gentamicin, and endolymphatic sac surgery for intractable vertigo in Meniere's disease. Otolaryngol Head Neck Surg 2001;125: 537-543.

21 Blakely BW: Update on intratympanic gentamicin for Ménière's disease. Laryngoscope 2000;110:236-240.

22 Hoffmann KK, Silverstein H: Inner ear perfusion: Indications and applications. Curr Opin Otolaryngol Head Neck Surg 2003;11:334339.

23 Marzo SJ, Leonetti JP: Intratympanic gentamicin therapy for persistent vertigo after endolymphatic sac surgery. Otolaryngol Head Neck Surg 2002;126:31-33.

24 Paparella MM, Fina M: Endolymphatic sac enhancement: Reversal of pathogenesis. Otolaryngol Clin North Am 2002;35:621-637.

25 Quaranta A, Aloisi A, De Benedittis G, Scaringi A: Intratympanic therapy for Ménière's disease. High-concentration gentamicin with round-window protection. Ann NY Acad Sci 1999;884:410-424.

26 Schwaber MK, Pensak ML, Reiber ME: Transmastoid labyrinthectomy in older patients. Laryngoscope 1995;105:1152-1154.

27 Cawthorne TE: The treatment of Ménière's disease. J Laryngol Otol 1943;58:363-371.

28 Langman AW, Lindeman RC: Surgical labyrinthectomy in the older patient. Otolaryngol Head Neck Surg 1998;118:739-742.

29 Langman AW, Lindeman RC: Surgery for vertigo in the nonserviceable hearing ear: Transmastoid labyrinthectomy or translabyrinthine vestibular nerve section. Laryngoscope 1993; 103:1321-1325.

30 Eisenman DJ, Speers R, Telian SA: Labyrinthectomy versus vestibular neurectomy: Longterm physiologic and clinical outcomes. Otol Neurotol 2001;22:539-548.

-31 Gacek RR, Gacek MR: Comparison of labyrinthectomy and vestibular neurectomy in the control of vertigo. Laryngoscope 1996;106: 225-230.

32 Portman G: The saccus endolymphaticus and an operation for draining the same for relief of vertigo. J Laryngol Otol 1927;42:809-817.

33 Ostrowski VB, Kartush JM: Endolymphatic sac-vein decompression for intractable Ménière's disease: Long-term treatment results. Otolaryngol Head Neck Surg 2003;128:550559.

34 Gianoli GJ, Larouere MJ, Kartush JM, Wayman J: Sac-vein decompression for intractable Ménière's disease: Two-year treatment results. Otolaryngol Head Neck Surg 1998;1 18:22-29.

>35 Glasscock ME 3rd, Jackson CG, Poe DS, Johnson GD: What I think of sac surgery in 1989. Am J Otol 1989;10:230-233.
36 Brackmann DE, Nissen RL: Ménière's disease: Results of treatment with the endolymphatic subarachnoid shunt compared with the endolymphatic mastoid shunt. Am J Otol 1987;8: 275-282.

37 Yazawa Y, Suzuki M, Kitano H, Kitajima K: Intraoperative mitomycin $\mathrm{C}$ in endolymphatic sac surgery for Ménière's disease: A pilot study. ORL J Otorhinolaryngol Relat Spec 1999;61: 188-194.

38 Kitahara T, Takeda N, Mishiro Y, Saika T, Fukushima M, Okumura S, Kubo T: Effects of exposing the opened endolymphatic sac to large doses of steroids to treat intractable Ménière's disease. Ann Otol Rhinol Laryngol 2001;110:109-112.

39 Thomsen J, Bretlau P, Tos M, Johnsen NJ: Placebo effect in surgery for Ménière's disease: Three-year follow-up. Otolaryngol Head Neck Surg 1983;91:183-186.

40 Thomsen J, Bonding P, Becker B, Stage J, Tos $\mathrm{M}$ : The non-specific effect of endolymphatic sac surgery in treatment of Ménière's disease: A prospective, randomized controlled study comparing 'classic' endolymphatic sac surgery with the insertion of a ventilating tube in the tympanic membrane. Acta Otolaryngol 1998;118: 769-773.

41 Thomsen J, Kerr A, Bretlau P, Olsson J, Tos M: Endolymphatic sac surgery: Why we do not do it. The non-specific effect of sac surgery. Clin Otolaryngol 1996;21:208-211.

42 Welling DB, Pasha R, Roth LJ, Barin K: The effect of endolymphatic sac excision in Ménière disease. Am J Otol 1996;17:278-282.

43 Huang TS: Endolymphatic sac surgery for Ménière's disease: Experience with over 3,000 cases. Otolaryngol Clin North Am 2002;35: 591-606.

44 Kerr AG: Emotional investments in surgical decision making. J Laryngol Otol 2002;116: 575-579.

45 Jones R, Silverstein H, Smouha E: Long-term results of transmeatal cochleovestibular neurectomy: an analysis of 100 cases. Otolaryngol Head Neck Surg 1989;100:22-29.

46 Frazier $\mathrm{CH}$ : Intracranial division of the auditory nerve for persistent aural vertigo. Surg Gynecol Obstet 1912;15:524-529.

47 McKenzie KG: Intracranial division of the vestibular portion of the auditory nerve for Ménière's disease. Can Med Assoc J 1936;34:369_ 391.

48 Dandy WE: Ménière's disease: Its diagnosis and method of treatment. Arch Surg 1928;16: 1127-1152.

49 Perry RH: A case of tinnitus and vertigo treated by division of the auditory nerve. $\mathrm{J}$ Laryngol Otol 1904;19:402-405.

50 House WF: Surgical exposure of internal auditory canal and its contents through the middle cranial fossa. Laryngoscope 1961;71:13631385 . 
51 Fisch U: Vestibular and cochlear neurectomy. Trans Am Acad Ophthalmol Otolaryngol 1977; 78:252-254.

52 Glasscock ME, Kveton JF, Christiansen SC: Middle fossa neurectomy: An update. Otolaryngol Head Neck Surg 1984;92:216-220.

-53 Vernick DM: Infralabyrinthine approach to the internal auditory canal. Otolaryngol Head Neck Surg 1990;102:307-313.

-54 Silverstein H, Norrell H: Retrolabyrinthine surgery: A direct approach to the cerebellopontine angle. Otolaryngol Head Neck Surg 1980; 88:462-469.

-55 Silverstein H, Norrell H, Smouha E, Jones R: Retrolabyrinthine or retrosigmoid vestibular neurectomy: Indications. Am J Otol 1987;8: 414-418.

56 Silverstein H, Norrell H, Smouha E, Jones R: Combined retrolab-retrosigmoid vestibular neurectomy. An evolution in approach. Am J Otol 1989;10:166-169.

$\checkmark 57$ Goksu N, Bayazit Y, Beder L: Posterior fossa vestibular nerve section for the management of peripheral vertigo. Eur Arch Otorhinolaryngol 1999;256:230-232.

58 Iurato S, Onofri M: Long-term follow-up after middle fossa vestibular neurectomy for Ménière's disease. ORL J Otorhinolaryngol Relat Spec 1995;57:141-147.

>59 Rosenberg SI, Silverstein H, Hoffer ME, Thaler E: Hearing results after posterior fossa vestibular neurectomy. Otolaryngol Head Neck Surg 1996;114:32-37.

60 Wazen JJ, Caruso M: Tinnitus outcome in surgery for vertigo. Int Tinnitus J 1997;3:51-53.

-61 Goksu N, Bayazit YA, Abdulhalik A, Kemaloglu YK: Vestibular neurectomy with simultaneous endolymphatic subarachnoid shunt. Eur Arch Otorhinolaryngol 2002;259:243-246.
62 Moody-Antonio S, House JW: Hearing outcome after concurrent endolymphatic shunt and vestibular nerve section. Otol Neurotol 2003;24:453-459.

63 Franz P, Hamzavi JS, Schneider B, Ehrenberger K: Do middle ear muscles trigger attacks of Ménière's disease? Acta Otolaryngol 2003;123: 133-137.

64 Montandon P, Guillemin P, Hausler R: Prevention of vertigo in Ménière's syndrome by means of transtympanic ventilation tubes. ORL J Otorhinolaryngol Relat Spec 1988;50: 377-381.

65 Janetta PJ, Moller MB, Moller AR: Disabling positional vertigo. N Engl J Med 1984;310: 1700-1705.

66 Naraghi R, Geiger H, Crnac J, Huk W, Fahlbusch R, Engels G, Luft FC: Posterior fossa neurovascular anomalies in essential hypertension. Lancet 1994;344:1466-1470.

67 Parnes LS, Shimotakahara SG, Pelz D, Lee D, Fox AJ: Vascular relationships of the vestibulocochlear nerve on magnetic resonance imaging. Am J Otol 1990;11:278-281.

68 Brackmann DE, Kesser BW, Day JD: Microvascular decompression of the vestibulocochlear nerve for disabling positional vertigo: The House Ear Clinic experience. Otol Neurotol 2001;22:882-887.

69 Seo T, Tominaga S, Sakagami M: Relationship between neurological asymptomatic vertigo and the vertebrobasilar system as revealed by magnetic resonance angiography. ORL J Otorhinolaryngol Relat Spec 2000;62:63-67.

70 Ryu H, Yamamoto S, Sugiyama K, Nozue M: Neurovascular compression syndrome of the eighth cranial nerve. What are the most reliable diagnostic signs? Acta Neurochir (Wien) 1998; 140:1279-1286.
71 Applebaum EL, Valvassori GE: Auditory and vestibular system findings in patients with vascular loops in the internal auditory canal. Ann Otol Rhinol Laryngol Suppl 1984;112:63-70.

72 McCabe BF, Harker LA: Vascular loop as a cause of vertigo. Ann Otol Rhinol Laryngol 1983;92:542-543.

73 Hakuba N, Hato N, Shinomori Y, Sato H, Gyo $\mathrm{K}$ : Labyrinthine fistula as a late complication of middle ear surgery using the canal wall down technique. Otol Neurotol 2002;23:832-835.

74 Weider DJ: Treatment and management of perilymphatic fistula: A New Hampshire experience. Am J Otol 1992;13:158-166.

75 Fitzgerald DC: Perilymphatic fistula and Ménière's disease. Clinical series and literature review. Ann Otol Rhinol Laryngol 2001;110: 430-436.

76 Weber PC, Bluestone CD, Perez B: Outcome of hearing and vertigo after surgery for congenital perilymphatic fistula in children. Am J Otolaryngol 2003;24:138-142.

77 Goksu N, Bayazit Y, Kemaloglu Y: Endoscopy of the posterior fossa and dissection of acoustic neuroma. J Neurosurg 1999;91:776-780.

78 Brackmann DE, Anderson RG: Ménière's disease: Results of treatment with the endolymphatic subarachnoid shunt. ORL J Otorhinolaryngol Relat Spec 1980;42:101-118.

79 Paparella MM, Fina M: Endolymphatic sac enhancement: Reversal of pathogenesis. Otolaryngol Clin North Am 2002;35:621-637.

80 Silverstein H, Lewis WB, Jackson LE, Rosenberg SI, Thompson JH, Hoffmann KK: Changing trends in the surgical treatment of Ménière's disease: Results of a 10-year survey. Ear Nose Throat J 2003;82:185-187, 191-194. 